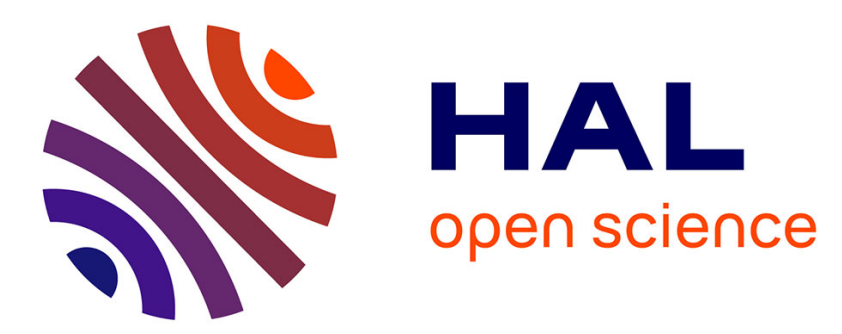

\title{
Plasma deposition of polymer composite films incorporating nanocellulose whiskers
}

\author{
P. Samyn, A. Airoudj, M.-P. Laborie, A.P. Mathew, V. Roucoules
}

\section{To cite this version:}

P. Samyn, A. Airoudj, M.-P. Laborie, A.P. Mathew, V. Roucoules. Plasma deposition of polymer composite films incorporating nanocellulose whiskers. European Physical Journal: Applied Physics, 2011, 56 (2), pp.24015. 10.1051/epjap/2011110170 . hal-00746203

\section{HAL Id: hal-00746203 https://hal.science/hal-00746203}

Submitted on 28 Oct 2012

HAL is a multi-disciplinary open access archive for the deposit and dissemination of scientific research documents, whether they are published or not. The documents may come from teaching and research institutions in France or abroad, or from public or private research centers.
L'archive ouverte pluridisciplinaire HAL, est destinée au dépôt et à la diffusion de documents scientifiques de niveau recherche, publiés ou non, émanant des établissements d'enseignement et de recherche français ou étrangers, des laboratoires publics ou privés. 


\title{
Plasma Deposition of Polymer Composite Films Incorporating Nanocellulose Whiskers
}

\author{
Pieter Samyn ${ }^{1}$ Aissam Airoudj ${ }^{2}$, Marie-Pierre Laborie ${ }^{1}$, Aji P. Mathew ${ }^{3}$, Vincent Roucoules ${ }^{2 *}$ \\ ${ }^{1}$ Albert-Ludwigs-Universität Freiburg, Institute for Forest Utilization and Works Science, \\ Werthmannstrasse 6, 79085 Freiburg, Germany \\ ${ }^{2}$ Université de Haute-Alsace, Institut de Science des Matériaux de Mulhouse \\ 15, Rue Jean Starcky, BP2488, 68057 Mulhouse Cedex, France \\ ${ }^{3}$ Lulea University of Technology, Department of Applied Physics and Mechanical
} Engineering, Division of Manufacturing and Design of Wood and Bionanocomposites, SE-97187 Lulea, Sweden

*Corresponding author: Vincent.Roucoules@ uha.fr

\begin{abstract}
In a trend for sustainable engineering and functionalisation of surfaces, we explore the possibilities of gas phase processes to deposit nanocomposite films. From an analysis of pulsed plasma polymerisation of maleic anhydride in presence of nanocellulose whiskers, it seems that thin nanocomposite films can be deposited with various patterns. By specifically modifying plasma parameters such as total power, duty cycle, and monomer gas pressure the nanocellulose whiskers are either incorporated into a buckled polymer film, or single nanocellulose whiskers are deposited on top of a polymeric film. The density of the latter can be controlled by modifying the exact positioning of the substrate in the reactor. The resulting morphologies are evaluated by optical microscopy, AFM, contact angle measurements and ellipsometry.
\end{abstract}

Keywords pulsed plasma, nanocellulose, maleic anhydride, nanocomposite 


\section{INTRODUCTION}

Chemical and topographic surface modifications allow to specifically control the interaction of solid bodies with their environment, influencing biological activity, friction coefficients, wear resistance, wetting phenomena and eventually surface transport properties. Organic thin films offer wide possibilities for surface functionalisation as they are soft and can be structured at lengthscales from the micro- to nanoscale range. Established techniques include self-assembly of block copolymers [1], or lithography [2-3]. As an alternative for conventional wet-chemical processes such as Langmuir-Blodgett and spin coating, plasma polymerisation has lower environmental impact and offers good flexibilty. It is therefore preferred as a solvent-free, low temperature technique that can be used in combination with a wide variety of substrates. The resulting polymer layer typically has high homogeneity and stability, depending on the degree of crosslinking. In addition, an amount of chemical functional sites can be maintained within the film through strict control of the deposition parameters. Additional features can be presented into plasma deposited organic films in combination with photolitographic patterning [4], doping [5] or interferometry [6].

In this research, we aim to design thin films with variable patterns, by incorporating nanocellulose as a renewable component into a plasma polymer film. The simultaneous processing of a relatively large fraction of natural materials contributes to more sustainable use of the available forest-based resources. Plasma polymerisation of maleic anhydride (MA) films is of particular interest for different applications [7-10], and often used as a platform for biosurface engineering [11]. However, relatively low energy inputs are required, and pulsed plasma processes [12] induce MA polymerisation by a radical chain growth mechanism [13, 14]. At the same time, the formation of reactive species within the plasma allows for possible interactions with other chemical moieties. As such, the co-deposition of polymer mixtures may be efficient for the formation of copolymers [15]. Also natural and renewable resources may be candidates to introduce in plasma films: e.g, cellulose has a stable glucose skeleton backbone and carries reactive hydroxyl groups at the side. After hydrolysis of cellulose pulps, nanocomponents such as nanocellulose whiskers can be separated with extremely high mechanical strength and stiffness $[16,17]$. At present, these nanocomponents are favourably used as reinforcement in polymeric composites [18, 19] or film formation [20, 21], but their ability for topographical structuring plasma films remains unexplored. In this report, we present the first results on the co-deposition of a plasma nanocomposite film and possibilities to create topographical patterns in combination with MA as a model monomer. In the context 
of sustainable design, we believe that others candidates as monomer could include biopolymers such as proteins or wood extractives. In order to tune the morphology of patterned nanocomposite films, we specifically focus on the specific control of the experimental plasma deposition conditions.

\section{EXPERIMENTAL DETAILS}

Nanocellulose whiskers (NW) were produced by sulphuric acid hydrolysis of microcrystalline cellulose, as reported by Bondeson et al [22]. The NW were subsequently freeze-dried and mixed with maleic anhydride (MA) monomer in a weight percent (wt.-\%) ratio of 1/200 $\mathrm{MA} / \mathrm{NW}$. The powder mixtures were contained in reactor tubes connected to the inlet of a low-temperature vacuum r.f. plasma reactor as described before [23]. Under evacuation of the plasma reactor, the monomer vapor was introduced in the reactor by sublimation at a constant flow rate of approximately $1.6 \times 10^{-9} \mathrm{~kg} \mathrm{~s}^{-1}$. The plasma was initiated through a high frequency generator and was applied for a total time of $30 \mathrm{~min}$ at pulse frequency $816 \mathrm{~Hz}$. The morphology of the polymerized films onto silica substrates was studied for following parameters of the pulsed plasma process: (i) plasma wave power output $P_{p}=10$ to $60 \mathrm{~W}$ at constant reflected power of maximum $2 \mathrm{~W}$, (ii) duty cycles $D C=t_{\text {on }} /\left(t_{\text {on }}+t_{\text {off }}\right)=2,25,50$ and $100 \%$, and (iii) monomer gas pressures between 0.1 to 0.2 mbar, or 0.2 to 0.4 mbar were applied by control of the vacuum in the reactor. Upon completion of deposition, the frequency generator was switched off while the monomer feed continued flowing for about 2 min prior to venting to atmospheric pressure and unloading the samples.

The morphology of resulting films on silica substrates were evaluated under atmospheric conditions by optical light microscopy (Leitz Metallux II, Wetzlar, Germany) and AFM measurements in tapping mode (Nanoscope IV, Digital Instruments). Tips with stiffness $k=$ $48 \mathrm{~N} \mathrm{~m}^{-1}$ and resonant frequency $f_{o}=190 \mathrm{kHz}$ were used (Nanoworld, type NCLR). The images were captured at an amplitude ratio of 1.2 , scanning rate of $0.88 \mathrm{~Hz}$ and 512 data points per line. The thickness $d$ and optical constant $n$ of the plasma films were estimated by ellipsometry (Multiskop M-033k001, Physik Instruments). The cross-section of the He-Ne laser beam $(632.8 \mathrm{~nm})$ has a spot size of about $1 \mathrm{~mm}^{2}$ and measurements were averaged over three places on the sample. Static contact angle measurements were taken on DSA 100 system (Krüss, Hamburg Germany), depositing $2 \mu$ high-purity water drops. The droplets were fitted with a tangent method and three independent measurements were done on films deposited on silicon substrates. 


\section{RESULTS AND DISCUSSION}

First, the plasma reactor was evacuated to ultra low vacuum ( 0.1 to $0.2 \mathrm{mbar})$, and different morphologies of plasma deposited nanocomposite films were studied by varying plasma powers and duty cycles, as presented in Figure 1 . Under mild conditions $\left(P_{p}=20 \mathrm{~W}, D C=2\right.$ $\%$ ), the substrate is completely covered by a film that incorporates the NC and polymerized MA. According to elipsometry and AFM image analysis, the patterned film has an average thickness about $d=90$ to $100 \mathrm{~nm}$. More severe plasma conditions with plasma power of $P_{p}=$ $60 \mathrm{~W}$ and higher duty cycles $D C=25,50$ or $100 \%$ result in less homogeneous films with single deposits that provide a locally patterned film, or multiple deposits that provide a film pattern through interferences controlling the local film orientation. The resulting film deposits are consequently somewhat thicker $(d=120$ to $150 \mathrm{~nm})$, and present a larger wavelength of the pattern. Continuous plasma depositions with $D C=100 \%$ often provide thick inhomogeneous and degraded nanocomposite films, as also frequently experienced for pure MA plasma films [9, 12]. This is likely due to monomeric fragmentation [24]. The contact angles measured on the nanocomposite film are 10 to $20^{\circ}$. Based on these experiences, the plasma conditions seem to control the formation of different morphologies controlled by metastable physical processes including buckling and dewetting, as further evaluated elsewhere in combination with chemical surface analysis [25].

Second, the plasma reactor was evacuated at medium vacuum (0.2 to $0.3 \mathrm{mbar})$ in combination with gently heating the monomer powder tube to about $35^{\circ} \mathrm{C}$ during the experiment. As such, nanocomposite films with fibrous morphologies were obtained, as presented in Figure 2. When putting the substrate at different positions in the reactor along the gas flow direction (i.e. length or direction) and parallel with the copper coil, the density of the deposited fibers varied with substrate location. The deposits were more dense near the entrance of the monomer gas feed (approximately $16 \mathrm{~cm}$ lateral distance from the monomer tube) and density gradually decreased towards the exit near the cold trap (approximately 20 $\mathrm{cm}$ lateral distance from the monomer tube). These morphological changes may possibly be caused by differences in the equilibrium ratio of NW to MA in the monomer gas mixture along the polymerization reaction in the reactor. However, the separated flux of NC and MA can not be controlled in the present setup. The contact angles measured on different positions on the substrate varied randomly between 38 and $45^{\circ}$, not uniquely correlating to the density and mostly depending on the presence of NC that dominates the hydrophilicity. 
Further analysis of the fibrous deposits gives interesting insight in the possible interactions of MA + NW mixtures along the gas flow. A scratch test on the deposited plasma film indeed confirms that a MA polymeric film adheres to the substrate and the NC are on top of it as fibrous structures (Figure 3). However, the thickness of the MA film varies over the substrate length, and is about $22 \pm 3 \mathrm{~nm}$ thick near the gas entrance (in agreement with the deposition of a pure MA film), and decreases in thickness to about $10 \pm 2 \mathrm{~nm}$ near the outlet, according to AFM measurements. This indicates that the MA monomers preferentially polymerize within the plasma and deposit on the substrate, while its concentration in the monomer gas stream consequently decreases gradually over the reactor length in favour of the NC concentration. The deposited fibers have a height of 60 to $80 \mathrm{~nm}$ above the surface, a width of $500 \mathrm{~nm}$ and length of 2 to $2.5 \mu \mathrm{m}$, according to AFM. Ellipsometry measurements indicate a thickness $d=50.2 \pm 2 \mathrm{~nm}$, and a refractive index $n=1.58$ for the overall film. The different thickness measurements agree amongst each other and indicate that the fibers are partly incorporated and mostly on top of the plasma polymerized MA film.

Some detailed micrographs give better insight into the behaviour of the freeze-dried nanowhiskers in presence of MA gas and a plasma reaction. Two different features can be distinguished, i.e. defibrillation observed near the reactor entrance with presumably high MA monomer concentration (Figure 4a) and crystal aggregation near the reactor outlet with presumably lower MA monomer concentration (Figure 4b). Initially, the freeze-dried NC are compacted and the powdery aggregates likely defibrillate into single fibers while carried in the monomer gas stream, before they are deposited on the substrate. Therefore, the MA gas may act as a dispersing medium that carries the NC aggregates and further defibrillates them by diffusion of the monomer gas from the borders towards the centre of the agglomerate. As the MA monomer concentration decreases along the reactor length while being polymerized, the interactions between the individual NC fibrils become more important and crystallite aggregates possibly form. It is known that elementary nanofibrils have strong tendency to coagulate and aggregate into secondary nanofibrils via lateral co-crystallization: this process was discovered as an irreversible aggregation of small nano-crystallites [26]: the secondary nanofibrils then further coagulate into nanofibrillar bundles that form lamellas, bands or layers of cellulose at several micrometer scales. 


\section{CONCLUSIONS}

We demonstrated that patterned nanocomposite films can be created by a gas phase process. As such, maleic anhydride films can be patterned during pulsed plasma polymerization by introducing nanocellulose whiskers (NW) in the monomer powder. For a fixed amount of nanowhiskers, the film morphologies can be adjusted by tight control of total plasma power, duty cycle, and monomer gas pressure. A regular thin film pattern is created at critical operation conditions of $20 \mathrm{~W}$ and duty cycles of $2 \%$, while more severe plasma deposition parameters cause locally coarse film structures and/or degraded structures. Depending on the control of the reactor pressure, a fibrous film is obtained with controllable features and densities depending on the substrate location in the reactor, including either defibrillation or crystal-like aggregates. Overall, the interest in this patterning method relies in the possibility to incorporate renewable resources into a plasma polymer film. We believe that the morphology is controlled by metastable nature of the visco-elastic polymer films, depending on the deposition conditions.

\section{Acknowledgements.}

P. Samyn acknowledges the Robert Bosch Stiftung GmbH for receiving financial support in the Juniorprofessorship program 2011-2016 'Sustainable Use of Natural Resources'.

\section{References.}

[1] T.B. Liu, C. Burger, B. Chu, Prog. Polym. Sci. 28, 5 (2003)

[2] Y. Xia, J. A. Rogers, K.E. Paul, G.M. Whitesides, Chem. Rev. 99,1823 (1999)

[3] S.Y. Chou, L. Zhuan, J. Vac. Sci. Technol. B 17, 3197 (1999)

[4] G. Mishra, C.D. Easton, S.L.McArthur, Langmuir 26, 3720 (2010)

[5] R.K. John, D.S. Kumar, J. Appl. Polym. Sci. 83, 1856 (2002)

[6] O. Soppera, A. Dirani, A. Ponche, V. Roucoules, Nanotechnol. 19, 395304 (2008)

[7] V. Roucoules, F. Siffer, A. Ponche, U. Egurrola, M.F. Vallat, J. Adhesion 83, 875 (2007)

[8] J. Hu, C. Yuin, H.Q. Mao, K. Tamada, W. Knoll, Adv. Funct. Mater. 13, 692 (2003)

[9] A.T.A. Jenkins, J. Hu, Y.Z. Wang, S. Schiller, R. Foerch, W. Knoll, Langmuir 16, 6381 (2000)

[10] S. Liu, M. Vareiro, S. Fraser, A.T.A. Jenkins, Langmuir 21, 8572 (2005). 
[11] T. Pompe, S. Zschoche, N. Herold, K. Salchert, M.F. Gouzy, C. Sperling, K. Werner, Biomacromolecules 4, 1072 (2003)

[12] M.E. Ryan, A.M. Hynes, J.P.S. Badyal, Chem. Mater. 8, 37 (1996)

[13] G. Mishra, S.L. McArthur, Langmuir 26, 9645 (2010)

[14] S. Schiller, J. Hu, A.T.A. Jenkins, R.B. Timmons, F.S. Sanchez-Estrada, W. Knoll, R. Förch, Chem. Mater. 114, 235 (2002)

[15] J. Drews, S. Goutianos, P. Kingshott, S. Hvilsted, N. Rozlosnik, K. Almdal, B.F. Sørensen, J. Vac. Sci. Technol. A 25, 1108 (2007)

[16] S.J. Eichhorn, Soft Matter 2, 303 (2011)

[17] A.S. Azizi Samir, F. Alloin, A. Dufresne, Biomacromolecules 6, 612 (2005)

[18] M. Jonoobi, J. Harun, A.P. Mathew, K. Oksman, Comp. Sci. Technol. 70, 1742 (2010)

[19] H. Lui, M.P. Laborie, Cellulose (to be published)

[20] S. Ahola, J. Salmi, L.S. Johansson, J. Laine, M. Österberg, Biomacromolecules 9, 1273 (2008)

[21] H. Qi, J. Cai, L. Zhang, S. Kuga, Biomacromolecules 10, 1597 (2009)

[22] D. Bondeson, A.P. Mathew, K. Oksman, Cellulose 13, 171 (2006)

[23] F.Siffer, A.Ponche, P.Fioux, J.Schultz, V. Roucoules Analytica Chimica Acta 539, 289, (2005).

[24] H.M. Kang, F. Basarir, K.Y. Paek, T.H. Yoon, J. Adhes. Interfac. 10, 17 (2009)

[25] P. Samyn, A. Airoudj, A.P. Mathew, V. Roucoules, M.-P. Laborie, Langmuir (2011)

Submitted

[26] M. Ioelovich, Bioresources 3, 1403 (2008) 
(a)

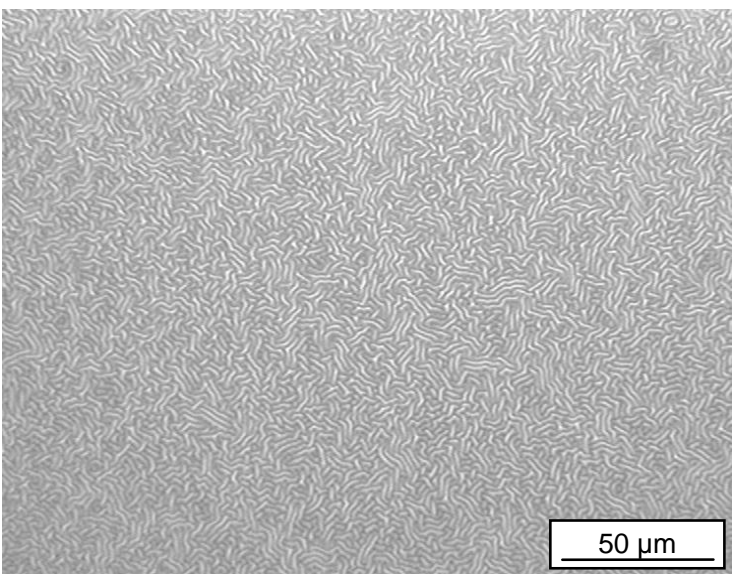

(c)

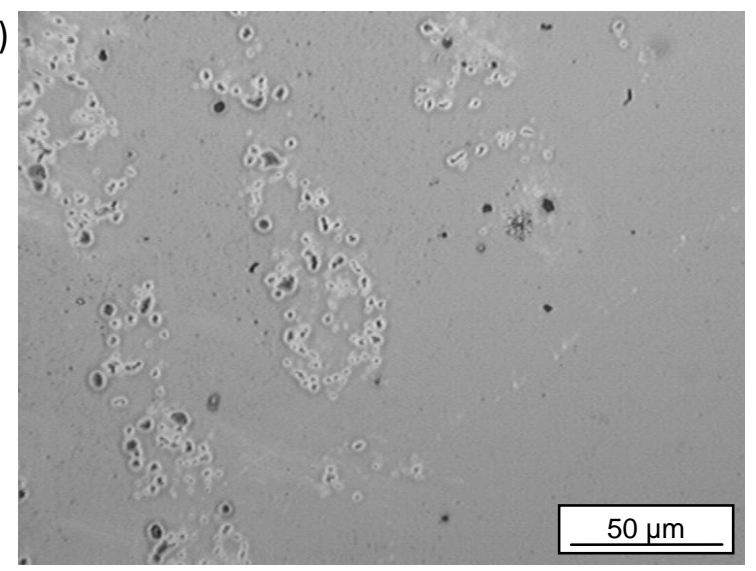

(b)

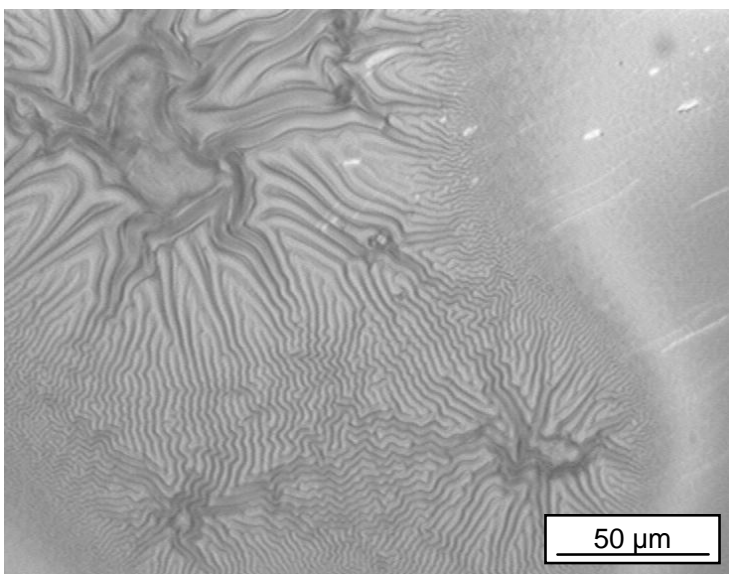

(d)

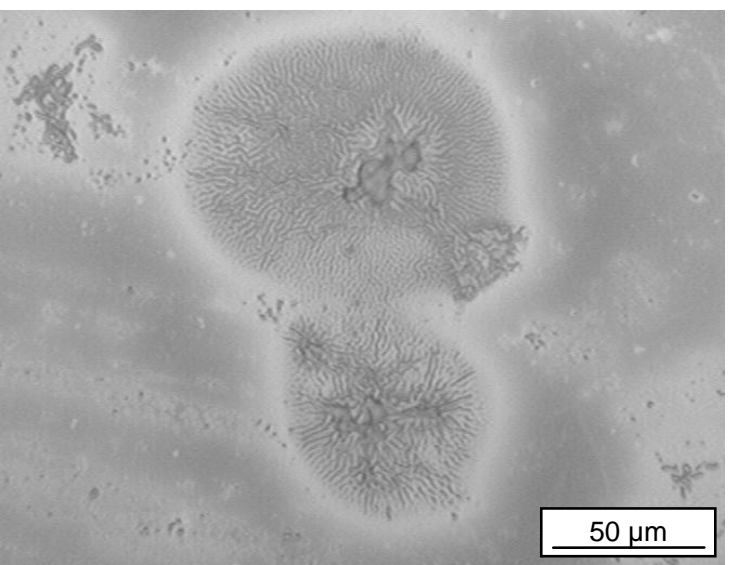

Figure 1. Morphologies of nanocomposite films with MA + 200 wt.- $\%$ NW under different plasma deposition conditions ( 0.1 to 0.2 mbar), including (a) $P_{p}=20 \mathrm{~W}, D C=2 \%$, (b) $P_{p}=$ $20 \mathrm{~W}, D C=50 \%$, (c) $P_{p}=20 \mathrm{~W}, D C=100 \%$, (d) $P_{p}=60 \mathrm{~W}, D C=2 \%$. 


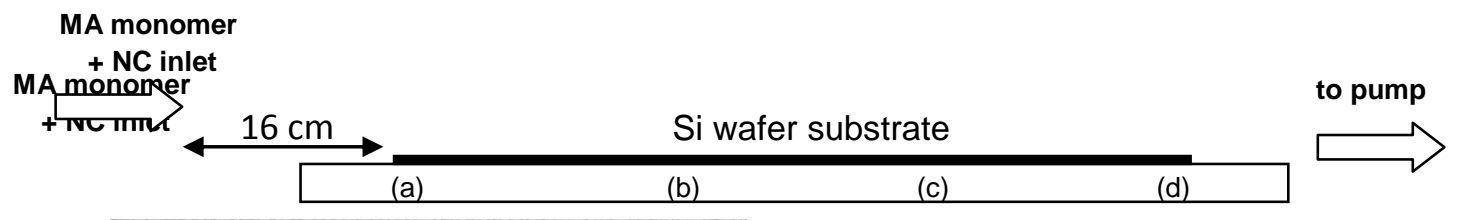

(a)
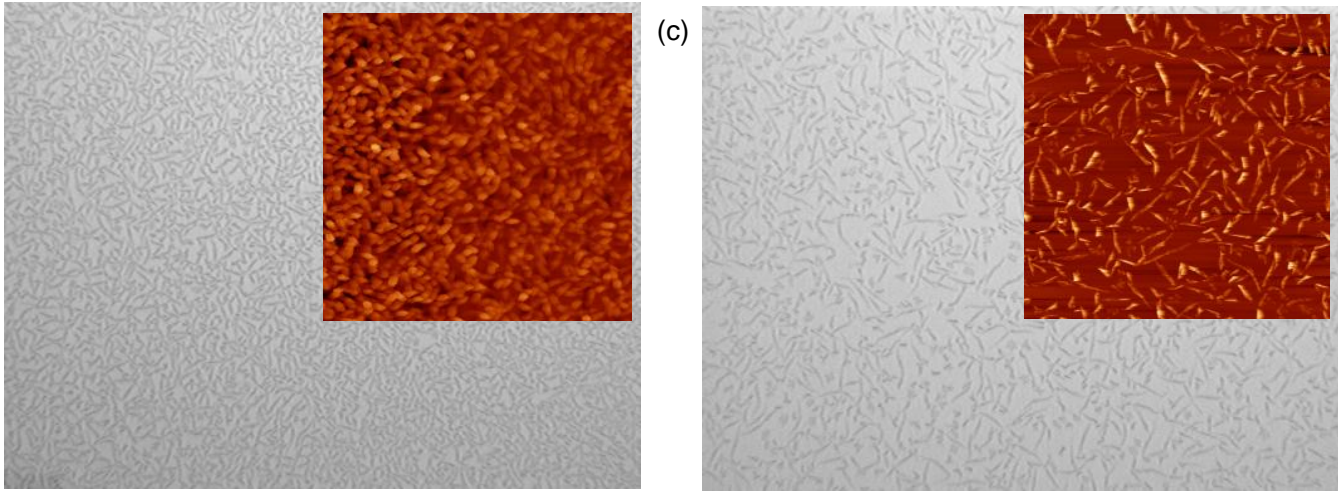

(b)

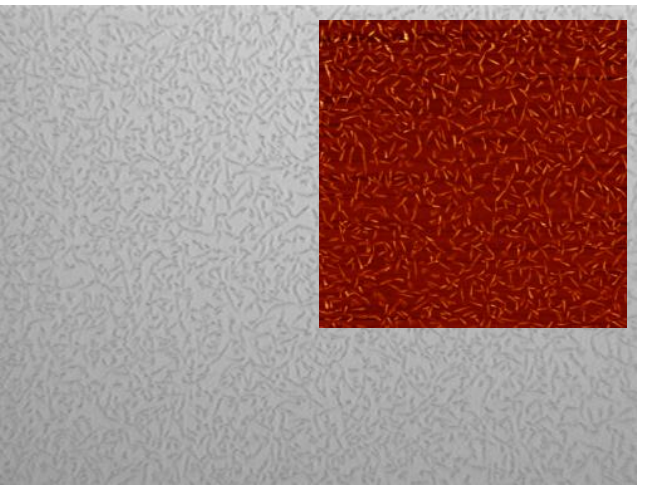

(d)

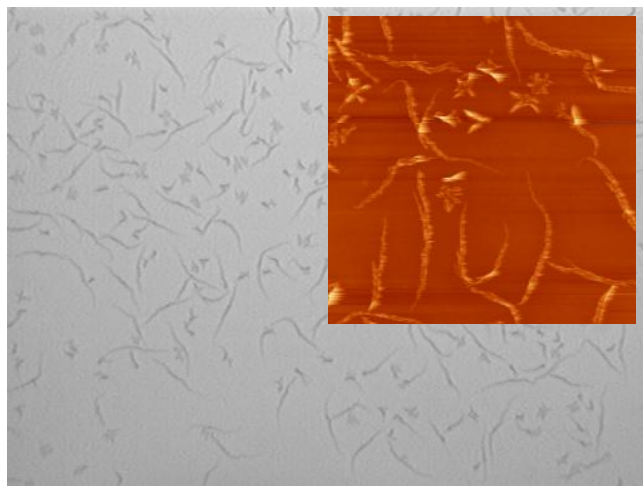

Figure 2. Morphologies of nanocomposite films with MA $+200 \mathrm{wt} .-\% \mathrm{NW}$ under different plasma deposition conditions ( 0.2 to $0.3 \mathrm{mbar}$ ), at different locations along the substrate (optical microscopy, inset AFM 50 x $50 \mu \mathrm{m}^{2}$ ). 


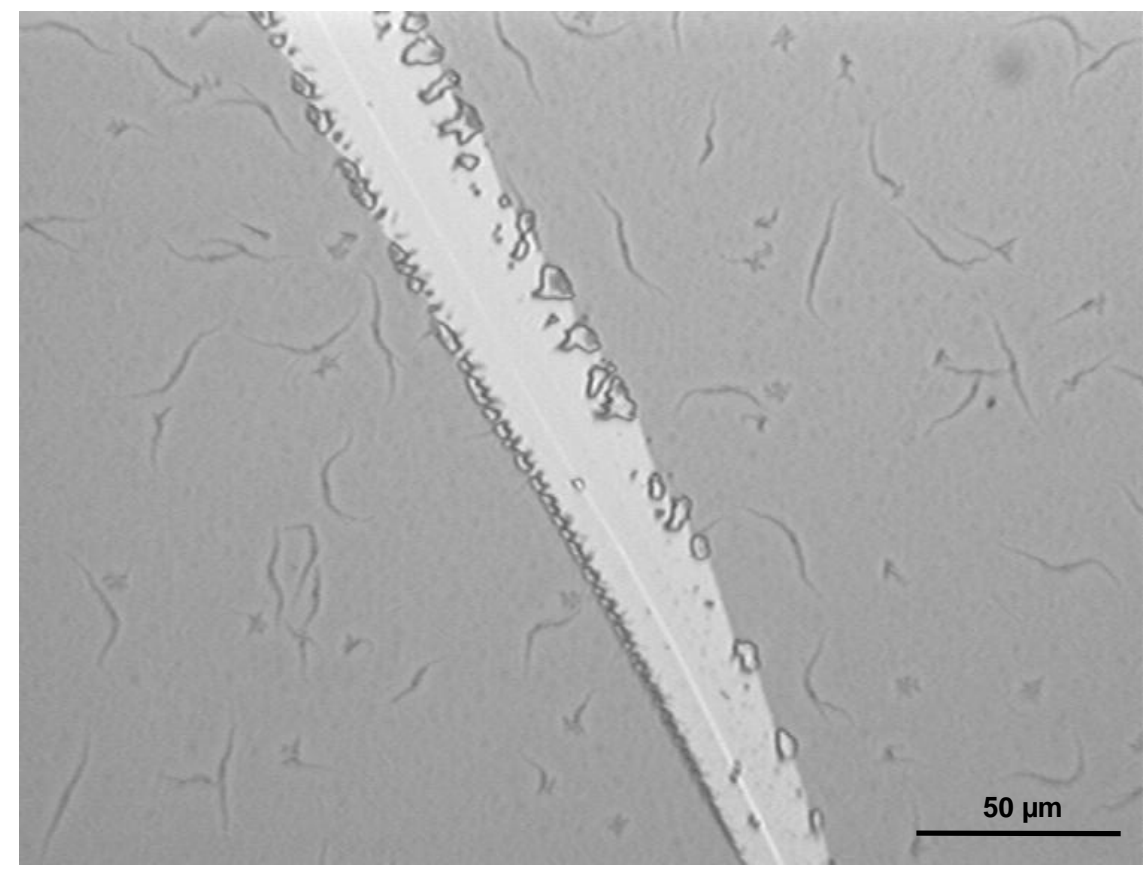

Figure 3. Scratch test on Si wafer substrate with plasma-deposited film of MA + 200 wt.-\% NW fibrous morphology 
(a)
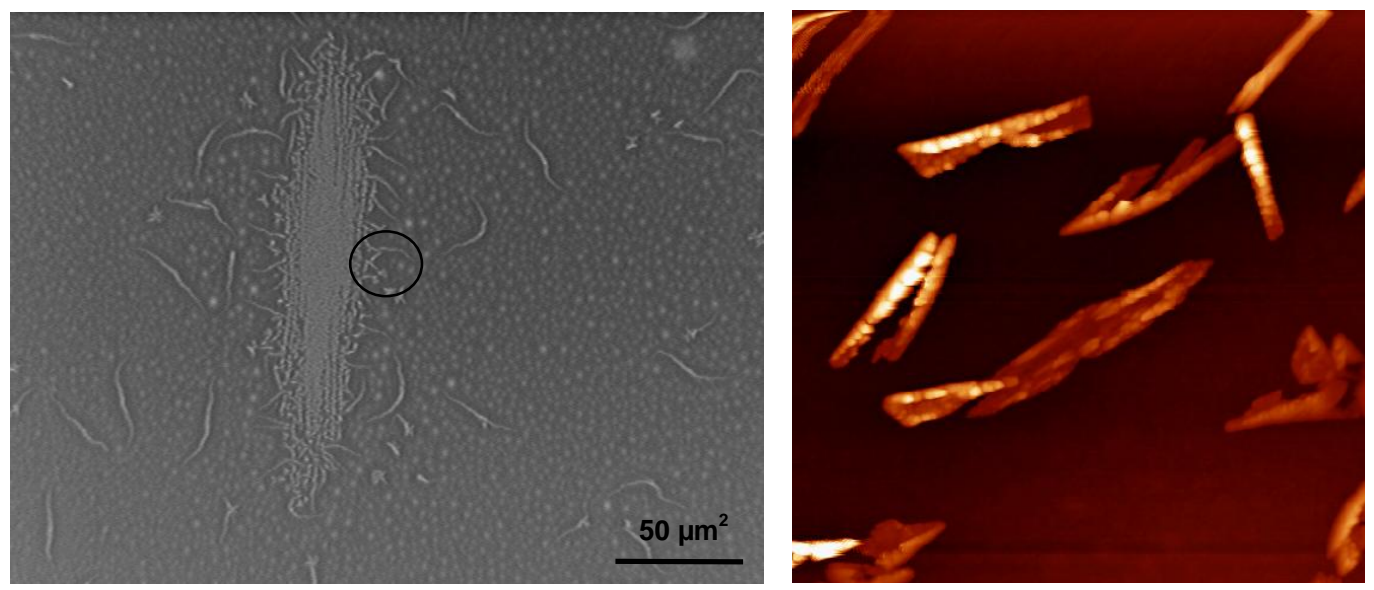

(b)
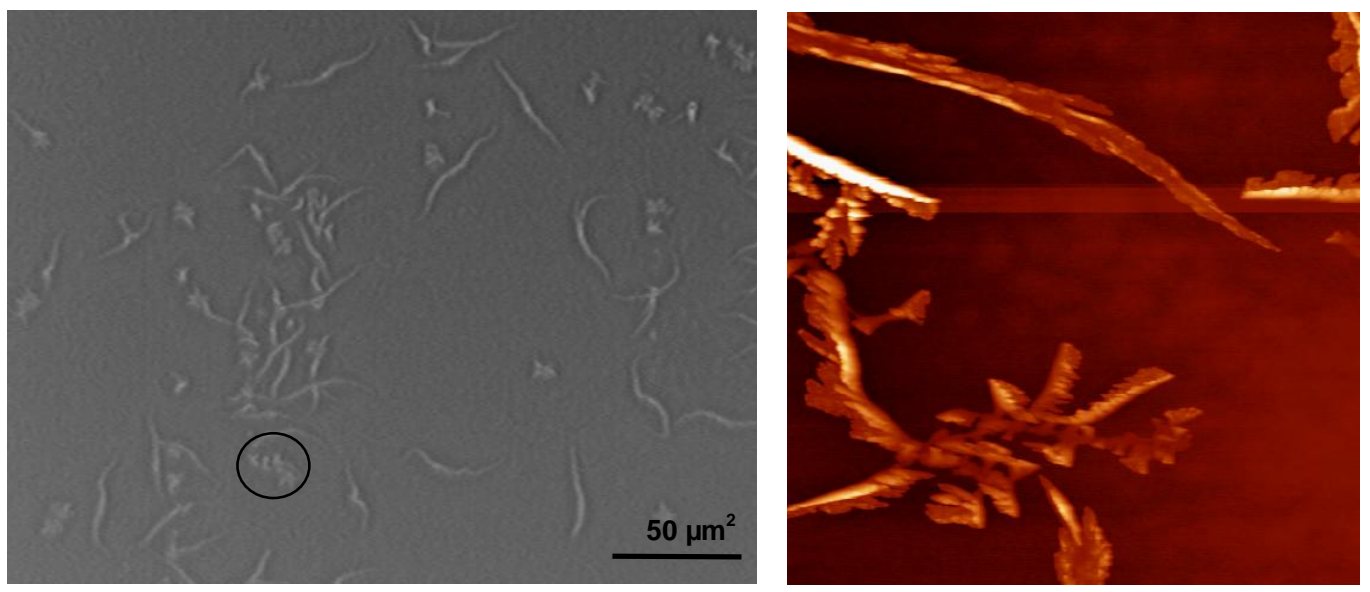

Figure 4. Detailed morphology of fibrous MA + $200 \mathrm{wt} .-\% \mathrm{NW}$ nanocomposite film (optical microscopy, AFM $10 \times 10 \mu \mathrm{m}^{2}$ ): (a) defibrillation, (b) agglomeration 